\title{
HOBBES, ROUSSEAU E KANT: UM DEBATE TEÓRICO SOBRE A GUERRA E A PAZ NO CENÁRIO INTERNACIONAL
}

HOBBES, ROUSSEAU AND KANT: A THEORETICAL DEBATE ON WAR AND PEACE

IN THE INTERNATIONAL SCENARIO

\section{Alana Camoça Gonçalves de Oliveira ${ }^{1}$}

\section{RESUMO}

A Guerra e a Paz são temas constantemente discutidos, mas não somente, em autores clássicos da Ciência Política e das Relações Internacionais, por esse motivo temos o interesse de trazer um debate teórico sobre o tema. Este artigo se propõe a estudar algumas das obras de Thomas Hobbes, Jean Jacques Rousseau e Immanuel Kant, com o intuito dialogar com os temas de guerra e paz em tais autores

PALAVRAS CHAVE: Thomas Hobbes; Jean Jacques Rousseau; Immanuel Kant

\begin{abstract}
War and peace are constantly discussed themes in classical authors of Political Science and International Relations, for this reason we are interested to bring a theoretical debate about this subject. This article aims to study the books of Thomas Hobbes, Jean Jacques Rousseau and Immanuel Kant, seeking to bring the prospects of war and peace from such authors.
\end{abstract}

KEYWORDS: Thomas Hobbes; Jean Jacques Rousseau; Immanuel Kant

\section{INTRODUÇÃO}

A guerra e a paz são temas debatidos desde a antiguidade, sendo uma das grandes inquietações no debate das Relações Internacionais. Existem diversas formas de se analisar a guerra, seja através de Clausewitz (s.d, p.75) para qual a "a guerra nada mais é do que um duelo em grande escala. Inúmeros duelos fazem uma guerra, mas pode ser formada uma imagem dela como um todo, imaginando-se um par de lutadores. (...) a guerra é, portanto, um ato de força para obrigar o nosso inimigo a fazer a nossa vontade" ou como nos clássicos orientais como a Arte da Guerra de Sun Tzu (2000, p.12) que argumenta sobre a importância da guerra para o Estado visto que "é o reino da vida e da morte. Dela depende a conservação ou a ruína do império".

\footnotetext{
${ }^{1}$ Doutoranda e Mestre em Economia Política Internacional na UFRJ. Bacharela em Ciência Política pela UNIRIO. Bolsista CAPES. E-mail: alanacamoca@gmail.com
} 
Para além da guerra, existem diversos autores que tem interesse em debater a paz em seus mais amplos significados como é o caso de São Tomás de Aquino (2000) que define a paz como "a tranquilidade da ordem" e até mesmo por Galtung (1969) que argumenta sobre a existência da Paz negativa e da Paz positiva ${ }^{2}$. Todavia, é preciso mencionar que é complexa a dissociação dos termos, visto que - em um argumento simplificado e não levando em considerações conceituações, apenas o momento da guerra ou o momento da paz - quando há ausência de guerra teríamos a paz e na ausência da paz, teríamos a guerra.

A amplitude do debate sobre guerra e paz é justificada pela relevância que a preservação da vida, a sacralidade da vida humana, o comportamento animalesco dos homens em situações adversas, as dissuasões como consequência da própria arquitetura do sistema internacional e a busca por poder são inquietações da sociedade. Nesse sentido, é com a ambição de estudar a guerra e os motivos que levaram as guerras travadas ao longo da história que inúmeros autores tentam compreender a natureza humana, o interesse nacional, os desejos expansivos dos Estados e o comportamento dos Estados no cenário internacional.

O debate sobre guerra e paz não é atual e muito menos está finalizado, existem diversos desdobramentos para compreender sobre tais conceitos no Sistema Internacional. 0 debate está em constante construção devido às novas formas de expressão da guerra pela conjuntura internacional quando a mesma ganha novas formas (cibernética, nuclear e etc) ou quando a busca por saná-la traz discursos pela paz embuídos de noções "civilizantes" ou como slogans de intervenções humanitárias que são temas centrais para compreender o jogo de poder no sistema internacional.

O objetivo deste artigo é colaborar para um debate sobre paz, guerra e sistema internacional por meio de uma análise de textos clássicos da Ciência Política, da Sociologia e das Relações Internacionais. São analisadas com maior ênfase as obras $O$ Leviatã de Thomas Hobbes (1588-1679), algumas das obras de Jean Jacques Rousseau (1712-1778) como Do Contrato Social e Extrato e Julgamento do Projeto de Paz Perpétua de Abbé de Saint-Pierre, por exemplo, e A Paz Perpétua de Immanuel Kant (1724-1804).

\footnotetext{
${ }^{2}$ De acordo com Galtung (1969) a Paz Negativa consistiria na ausência de violência direta, mas com a existência da manutenção de um cenário de violência estrutural. Já a Paz Positiva corresponde a ausência tanto da violência direta como da violência estrutural.
} 
Os autores escolhidos nesse artigo são pensadores que em algum momento de suas vidas e suas obras visam debater a antropologia humana e a necessidade do estabelecimento de uma paz no sistema internacional alicerçada ou em figuras soberanas ou formas de governo ou ainda em visões cosmopolitas de Sociedade Internacional. 0 artigo está dividido em três partes para além da introdução e da conclusão. As três partes que constituem o artigo tem como objetivo analisar as obras dos três autores escolhidos para debater a paz e a guerra no cenário internacional para que na conclusão sejam pontuadas as diferenças e semelhanças encontradas em suas obras.

\section{THOMAS HOBBES: A ANARQUIA, A GUERRA E A CONSTANTE BUSCA PELA SEGURANÇA}

Iniciaremos o debate com Thomas Hobbes (1588 -1679), o filósofo nasceu na dinastia Tudor (1485-1603) sendo influenciado pela reforma anglicana que ocorreu cinco décadas antes. Durante sua vida Hobbes vivenciou as grandes e decisivas transformações inglesas do ponto de vista político, econômico e, inclusive, territorial com a sua ascensão como potência mundial do séculos XVI até o século XIX.

Como alguns dos acontecimentos do período, elenca-se no século XVII i) o expansionismo colonialista ultramarino inglês que começou e ganhou forças com a criação da Companhia das Índias Orientais Inglesas em 1600; ii) o estabelecimento da primeira colônia inglesa nas Américas em 1607, Jamestown; iii) e entre outros. Aos poucos a Inglaterra foi se consolidando como potência e grande poder marítimo no cenário internacional, mas apesar disso, do ponto de vista doméstico, viveu grandes disrupções políticas. Historicamente, em 1642 após conflitos originados em decorrência de dissuasões internas entre o rei e o parlamento foi deflagrada a Guerra Civil Inglesa (1642-1649), com conflitos advindos pela parte do rei Carlos I alicerçado na elite e na burguesia conservadora e do outro lado os parlamentares ${ }^{3}$

Não temos objetivo de debater o conflito inglês, mas ele foi o palco para os escritos de Hobbes que escreveu durante a efervescência de tal guerra. A necessidade de debater o autor em sua conjuntura temporal se justifica precisamente pelos sinais de um

\footnotetext{
${ }^{3}$ Para um maior debate sobre o tempo de Hobbes, consultar Thomas Hobbes in His Time editado por Ralph Ross, Herbert W. Schneider e Theodore Waldman.
} 
sentimento de aversão à insegurança gerada pelos climas revolucionários da época presente em sua obra. Nesse sentido, os conflitos entre o parlamento, as correntes religiosas e o poder da igreja, a questão do poder absoluto e o medo da morte violenta são elementos apresentados como preocupações nas obras de Hobbes.

A obra $O$ Leviatã, um dos principais livros do autor, mistura diversos temas e debate sobre a concepção das sensações, do Estado, da figura do soberano e - o tema que será desenvolvido - da Guerra e da Paz. Na construção de seu pensamento sobre o Estado, inicialmente, Hobbes discorre sobre o pensamento lógico para construir a razão e tal movimento é o que permitiria ao homem ter instintos referentes à conservação e a preservação, um instinto que caracteriza o esforço humano comum a todos os seres para aproximar-se ao que lhes agrada e fugir do que lhes desagrada. Nesse sentido "o homem pode raciocinar, ou calcular, não apenas sobre números, mas sobre todas as demais coisas que podem ser somadas a ou subtraídas de outras. Esse privilégio está associado a um outro: refiro-me ao privilégio do absurdo, ao qual nenhuma criatura viva além do homem está sujeita" (HOBBES, 2009, p. 43).

Hobbes qualifica o homem como uma criatura racional, mas entende a falibilidade humana compreendendo que existiriam três paixões fundamentais para o ser humano, sendo elas: i) a vanglória, ii) a competição e iii) a desconfiança. Tais paixões também podem ser pensadas na esfera internacional, como veremos adiante. Enquanto a competição impulsiona os homens a se atacarem para lograr algum benefício, a desconfiança garantiria a segurança e a glória traria a reputação.

Sem o Estado Civil os homens viveriam no chamado "Estado de Natureza", um ambiente marcado pela discórdia, pelo medo e pela guerra de todos contra todos. Logo, neste cenário de guerra existiria uma sensação permanente de medo da morte violenta e por esse motivo, o homem seria desconfiado e buscaria incessantemente sua autopreservação.

\footnotetext{
Mas mesmo que jamais tivesse havido um tempo em que os indivíduos se encontrassem numa condição de guerra de todos contra todos, de qualquer modo em todos os tempos os reis, e as pessoas dotadas de autoridade soberana, por causa de sua independência vivem em constante rivalidade, e na situação e atitude dos gladiadores, com as armas assestadas, cada um de olhos fixos no outro; isto é, seus fortes, guarnições e canhões guardando as fronteiras de seus reinos, e constantemente com espiões no território de seus vizinhos, o que constitui uma atitude de guerra. (...) Desta guerra de todos os homens contra todos os homens também isto é conseqüência: que nada pode ser injusto. As noções de bem e de mal, de justiça e injustiça, não podem aí ter lugar. Onde não
} 
há poder comum não há lei, e onde não há lei não há injustiça. (...) As paixões que fazem os homens tender para a paz são o medo da morte, o desejo daquelas coisas que são necessárias para uma vida confortável, e a esperança de conseguilas através do trabalho (HOBBES, 2009, p.81).

$\mathrm{Na}$ concepção hobbesiana a guerra tem origens na igualdade entre os homens, visto que sem um soberano a guerra é inevitável. A partir do momento em que existe a igualdade entre os homens, nasce a desconfiança de um em relação ao outro e para controlar os impulsos é necessária a existência de um soberano, de alguma forma de governo, para que não se perpetue a guerra incessante. No Estado hobbesiano, o Estado Civil, a figura do Leviatã ${ }^{4}$ é capaz de reprimir a guerra, impondo a paz civil instituída pelo Estado e assegurada por regras e leis que controlam ou punem os impulsos dos homens.

Segundo o autor, o soberano tem o papel fundamental de legislador, visto que no Estado de Natureza existiria a igualdade e nesse momento qualquer homem pode ferir aos demais, porque todos têm igual direito a todas as coisas, já que não há uma regra que estabeleça limitações. Logo, sem um juiz das ações humanas, sempre haveria disputa sobre a justiça e a injustiça, sobre o que é certo e errado e os riscos do homem tirar a vida de outrem para atingir suas finalidades, em busca da sua paz individual, da sua segurança é constante.

De forma resumida, a justificativa do Estado reside na busca pela autopreservação, na saída de um mundo de inseguranças para um mundo regido por leis civis capazes de refrear os impulsos. 0 poder absoluto de Hobbes é peculiar e afirma-se que o Estado é instituído no momento em que a multidão de homens concordam, consentem e pactuam a qualquer homem ou assembleia de homens à autorização de atos e decisões, tal como se fossem os próprios atos e decisões do povo, com o único intuito de viver em paz e, o mais importante, a segurança.

Hans Morgenthau (2003, p.116) em sua obra Política entre as Nações recupera o debate hobbesiano tentando explicitar e sistematizar o pensamento de Hobbes para a as Relações Internacionais. Um dos pilares de apoio de Morgenthau é a máxima do realismo a respeito do incessante pelo poder e a partir desta máxima o autor argumenta que os

\footnotetext{
${ }^{4}$ A paz é um objetivo oriundo do desejo dos homens não morrerem violentamente e para cumprir tal desejo é necessária figura do Leviatã, "o Deus mortal a quem devemos, abaixo de Deus imortal, nossa paz e defesa. O Estado, que é autorizado por cada um, é capaz de conformar todas as vontades, a fim de garantir a paz em seu país, e promover a ajuda mútua contra os inimigos estrangeiros” (HOBBES, 2009, p. 126).
} 
exemplos históricos do "imperialismo ilimitado (...) apresentam em comum um ímpeto pela expansão que desconhece quaisquer limites racionais, que se alimenta de seus próprios êxitos e que, se não for detido por uma força superior, se estenderá até os últimos confins do mundo político".

\begin{abstract}
Assinalo assim, em primeiro lugar, como tendência geral de todos os homens, um perpétuo e irrequieto desejo de poder e mais poder, que cessa apenas com a morte. $\mathrm{E}$ a causa disto nem sempre é que se espere um prazer mais intenso do que aquele que já se alcançou, ou que cada um não possa contentar-se com um poder moderado, mas o fato de não se poder garantir o poder e os meios para viver bem que atualmente se possuem sem adquirir mais ainda. E daqui se segue que os reis, cujo poder é maior, se esforçam por garanti-lo no interior através de leis, e no exterior através de guerras. E depois disto feito surge um novo desejo, em alguns, de fama por uma nova conquista, em outros, de conforto e prazeres sensuais, e em outros de admiração, de serem elogiados pela excelência em alguma arte, ou outra qualidade do espírito (HOBBES, 2009, p.36).
\end{abstract}

Nessa incessante busca por poder, os Estados travariam guerras ou ficariam sempre em estado de tensão diante da incapacidade e da desconfiança em um sistema que não detém um soberano ou poder comum. 0 Estados viveriam em um ambiente anárquico onde inexistiria a ordem, mas isso não quer dizer necessariamente que os países sempre guerreariam, mas sim que estariam sempre predispostos e precisariam estar prontos a fazê-lo.

Na obra do Cidadão (1983, p.159) Hobbes descreve sua concepção fundada em um cenário de hostilidades no nível internacional afirmando que for the state of Commonwealths considered in themselves, is natural, that is to say, hostile; neither if they cease from fighting, is it therefore to be called Peace, but rather a breathing time, in which one enemy observing the motion and countenance of the other, values his security not according to the Pacts, but the forces and counsels of his adversary (...).

Ainda sim, é preciso enfatizar que Hobbes sustenta em seu argumento a necessidade de um estudo detalhado sobre o poder e os interesses dos países vizinhos, na tentativa de preservação da paz e da ausência da sensação de ameaças e da morte violenta.

... by reason of a Common-wealth, we must not only understand matters at home, of the but Forraing Affaires too: at Home, by what goods the Country is nourished, and defended, and whence they are fetched; what places are fit to make Garrisons of; by what means souldiers are best to be raised, and maintained; what manner of affections the subjects bear toward their Prince (...) Abroad, what the power of each neighboring country is, and wherein it consists; what advantage, or disadvantage we may receive from them; what their 
dispositions are both to us-war, and how affected to each other among themselves, (....) (HOBBES, 1983, p.137).

O argumento de Hobbes é que não há no cenário internacional uma força capaz de manter a paz e impedir que os Estados, que buscam acumular poder, freiem seus desejos de expansão. Como o sistema internacional é composto de Estados independentes e soberanos, sobre eles não há um poder comum capaz de submetê-los as mesmas leis, não existe um Leviatã.

Portanto, no nível doméstico, Hobbes enumera motivos para a necessidade da autoridade soberana do Leviatã, mas não resolve o problema da anarquia internacional ${ }^{5}$ e se recusa a argumentar sobre a ideia de um "Estado Mundial" 6 . Este é um dos debates de autores que decidiram revisitar a o debate hobbesiano como Bull (1981), Williams (1996) e outros. Além disso, os autores também argumentam que é preciso abrir a caixa preta a respeito da teoria hobbesiana e entender que para além do desejo pela guerra e por poder, a interpretação de Hobbes deveria ser pensada na guerra não como um desejo, pelo contrário, o Estado e o homem, dotado de impulsos e paixões que desejam a paz.

\section{JEAN JACQUES ROSSEAU: O PESSIMISMO SOBRE A GUERRA E A PAZ}

Jean Jacques Rousseau (1712-1778) escreveu no século XVII no período do Iluminismo, momento em que a Europa vivia lutas sociais e assistia a ascensão da burguesia. Rousseau é conhecido como um dos teóricos da Revolução Francesa (1789) mesmo que não tenha a vivenciado. Por ter vivido na França, presenciou as tensões da época, os conflitos entre a burguesia e a monarquia em busca de transformações no cenário francês.

O autor analisa a Europa e a França percebendo em suas estruturas os obstáculos impostos à vida do homem e algumas de suas potencialidades naturais. É a partir de um pensamento crítico sobre a sociedade que Rousseau desenvolveu obras como Discurso Sobre a origem e os fundamentos da desigualdade entre os homens, Do Contrato Social,

\footnotetext{
${ }^{5}$ A anarquia é um conceito discutido nas relações internacionais por diversos autores, sejam os clássicos, modernos e pós-modernos. Para um debate mais intenso sobre tal conceito, sugere-se a leitura de textos de Heddley Bull (1981) , Edward Keene (2004) e Nicholas Onuf (2015), por exemplo.

${ }^{6}$ Para um debate aprofundado sobre tal temática ver em Williams, 1996. 
Considerações Sobre o Governo da Polônia e a sua projetada Reforma e outras que trataremos aqui.

Segundo Sarti (2012) as obras de Rousseau são uma crítica à economia política do capitalismo e, assim como Hobbes, a abordagem de Rousseau não é propriamente histórica, e sim uma reflexão atemporal. 0 homem rousseauniano é conduzido pela compaixão, mas é importante apontar que o homem de Rousseau também é competitivo, tem características de vaidade e inveja dentro de si, aquilo que ele chamou de "amor próprio"7.

Em suas teses, além de compreender e criticar a situação do mundo, o objetivo de Rousseau era reformular os valores humanos, propondo a reconstrução das relações sociais em concordância com a natureza humana. A concepção de natureza humana de Rousseau, diferente de Hobbes, concebe o homem como o mito do "bom selvagem". Para tanto, diferente do Estado de Natureza hobbesiano, para Rousseau, o Estado de Natureza divide-se em dois momentos: i) o primeiro seria no momento em que há plena felicidade humana e liberdade, onde os homens viveriam isoladamente e guiados pelos instintos. Nesse primeiro momento inexistiriam relações sociais, religiosas, afetivas, sem a noção de bem ou mal, nem propriedade e nem justiça (SARTI, 2012; HOFFMAN, 1963; LEOPOLDI, 2002). Os homens só seguiriam à própria razão, sendo esta uma das principais características do homem rousseauniano e ii) no momento em que o homem passa a se socializar e viver em sociedade, temos o fim deste Estado quando inicia-se a história, às convenções sociais e, principalmente, a desigualdade. Estas desigualdades sociais estimulam a criação do primeiro contrato, um contrato desigual que tornou o homem servo de um sistema vicioso (LEOPOLDI, 2002; ROUSSEAU, 2011).

Esta sociedade tem como fruto a desigualdade, uma vez que, como argumenta Sarti (2012, p.9), os homens não conseguindo manter a ordem fazem o primeiro contrato e como os "homens não possuíam experiência para prever os perigos de uma formação política e, embora sentissem a necessidade de alguma regulamentação, só raciocinavam sobre os interesses imediatos. Por isso aceitaram as leis de um governo despótico submetendo-se à escravidão quando acreditavam que se asseguravam a liberdade".

\footnotetext{
${ }^{7}$ Para um debate amplo sobre o tema consultar Sarti (2012) e Weffort (2011).
} 
Como crítica desse processo civilizatório e das suas consequências negativas, Rousseau criou a teoria do Contrato Social alicerçada na alienação da vontade de todos e dos interesses particulares para o que ele chamou de "vontade geral". Nesse contrato “cada um de nós dispõe em comum da sua pessoa e de todo o seu poder sob a suprema direção da vontade geral, e recebe, enquanto corpo, cada membro como parte indivisível do todo." (ROUSSEAU, 2011).

Não é de interesse do artigo debater as especificidades e alguns dos conceitos relativos ao Contrato Social rousseauniano, mas sim adentrarmos no pensamento do autor sobre a guerra e a paz. Usualmente, os estudos sobre Rousseau tendem a encará-lo somente a partir de uma perspectiva e concepção de sua teoria do ponto de vista doméstico, mas é possível enxergar em seus argumentos teóricos uma análise do sistema interestatal, um pensamento que transita entre a utopia de uma paz internacional e o realismo pessimista (SARTI, 2012, p.14).

Neste momento, avançando para o debate sobre guerra e paz, trataremos de forma mais específica cinco escritos de Rousseau debatendo a paz e a guerra nas relações internacionais: i) Do Contrato, ii) Considerações Sobre o Governo da Polônia e a sua projetada Reforma (1772), iii) Extrato e Julgamento do Projeto de Paz Perpétua de Abbé Saint Pierre (1756), iv) Fragmentos sobre a Guerra (1755-1756) e v) o Estado de Guerra Nascido do Estado Social (1755-1756).

Na obra o Estado de Guerra Nascido do Estado Social (1755-1756) Rousseau, em uma crítica a Hobbes, argumenta que o homem é naturalmente pacífico e medroso e não existindo uma inclinação natural no homem para que guerreie com os seus semelhantes, não há, portanto, "guerra geral entre os homens". Além disso, em um momento de guerra "mata-se para poder vencer, e não há homem bestial o bastante para buscar a vitória a fim de matar" (ROUSSEAU, 2003b, p.63).

O autor argumenta que a guerra não pode ser vista como uma relação entre indivíduos, mas sim entre Estados, por esse motivo "o estrangeiro que rouba, pilha e prende sem que a guerra seja declarada não é um inimigo, mas um bandido" (ROUSSEAU, 2003b, p.64) e como citado em Do Contrato Social “o estrangeiro, seja rei, particular, ou povo, que roube, mate ou detenha os vassalos, sem declaração de guerra ao príncipe, não é um inimigo, é um salteador" (ROUSSEAU, 2011). 
No Extrato e Julgamento do Projeto de Paz Perpétua de Abbé Saint Pierre (1756), discutindo sobre a paz, Rousseau elogia o pensamento a respeito de uma paz perpétua e universal entre os povos da Europa afinal, “quem não preferiria as ilusões de um espírito generoso, que supera todos os obstáculos, à razão seca e repulsiva, cuja indiferença ao bem-estar da humanidade é sempre o principal obstáculo a todos os esquemas destinados a alcançá-lo?" (ROUSSEAU, 2003c, p.77).

Todavia, Rousseau busca demonstrar a inviabilidade da proposta de Abbé Saint Pierre $^{8}$ através de uma análise realista do mundo, critica a utopia sobre a paz e ao mesmo tempo o cenário conflituoso das relações internacionais quando argumenta que a necessidade de desviar as atenções para a segurança externa faz com que o homem não promova o bem interno do Estado. Para tanto, a obra dedicada a desmistificar a possibilidade da instituição proposta por Abbé Saint Pierre, sendo a obra de Rousseau que mais nos dá pistas sobre seu pensamento a respeito da guerra e do sistema internacional.

Refletindo sobre a Europa, argumenta como a região poderia ser mais pacífica, tendo em vista que "a Europa, centro dos poderes temporal e espiritual, guarda ainda um sentido de associação mais intenso do que o encontrado em outras regiões. Nos outros continentes as nações estão por demais dispersas para manter uma associação recíproca; e falta-lhes qualquer outro ponto de união, como o da Europa" (ROUSSEAU, 2003c; p.77), mas apesar dessa utopia sobre a paz existem disputas permanentes, revoltas, guerras, crueldade, homicídios e nesse cenário os discursos sobre a humanidade ilimitada são contrapostos com os atos abomináveis cometidos pelos homens. A crítica rousseauniana pode ser resumida na seguinte citação:

A união histórica das nações européias emaranhou seus interesses e direitos em mil complicações; elas se tocam em tantos pontos que nenhuma delas pode mover-se sem imprimir um impulso a todas as outras; como os laços que as unem são mais estreitos, seus movimentos podem ter conseqüências mortais, e seus freqüentes conflitos são quase tão selvagens quanto as guerras civis. Devemos admitir assim que as potências européias se posicionam entre si estritamente em

\footnotetext{
${ }^{8}$ A tese central de Abbé Saint Pierre é ao refletir sobre a necessidade de paz e a ineficácia da existência da mesma através das promessas escritas em Tratados de Comércio e Armistícios de Paz. Como a i) constituição da europeia não permitiria só produziria guerras contínuas e ii) o equilíbrio de poder entre a Casa da França e da Áustria não seria capaz de produzir segurança suficiente nem contra guerras externas, nem contra guerras civis, seria necessária um novo passo para tentar produzir esta paz que nas palavras do autor seria possível se "as dezoito soberanias principais da Europa, a fim de manter os governos atuais, evitar a Guerra entre si e obter todas as vantagens de um comércio perpétuo de Nação a Nação, resolvessem fazer um Tratado de União e um Congresso permanente, mais ou menos segundo o modelo, ou das sete soberanias da Holanda, ou das treze soberanias dos suíços ou das soberanias da Alemanha, e formar uma União Europeia baseada nas virtudes de tais Uniões (...) os mais fracos teriam segurança suficiente de que o maior poder dos mais fortes nãos os poderia prejudicar, e de que cada qual manteria exatamente as promessas recíprocas" (SAINT PIERRE, 2003, pp.5-6).
} 
um estado de guerra, e que todos os tratados existentes entre elas são por sua natureza mais uma trégua temporária do que a paz genuína: seja porque esses tratados raramente são garantidos por outra potência além das contratantes, seja porque os respectivos direitos nunca são determinados precisamente, criando assim (...) a possibilidade de outras guerras, quando as circunstâncias mudam, trazendo novo alento aos postulantes (ROUSSEAU, 2003c, pp.76-77).

Em um cenário que todas as potências europeias têm entre si direitos ou pretensões é razoável considerar que não existe uma forma definitiva de se resolver disputas, seja pela inexistência de algum árbitro ou pela submissão de uma potência fraca à potência mais forte por meio de tratados antes ou depois de uma guerra. Indagando e questionando as teses de Abbé Saint Pierre, Rousseau questiona i) se a confederação sugerida poderia de fato estabelecer uma paz duradoura na Europa e ii) se os Estados teriam interesse de pagar os custos para instituir tal paz.

Ressalta-se que, diferente de Hobbes, Rousseau tem severas críticas a respeito da paz duradoura e sua existência, mas não assume a guerra de todos contra todos como um imperativo. Ao contrário, Rousseau compreende que a dificuldade de tal paz duradoura reside no "struggle in which the existence of even one "relationship of major tension" may make amity impossible and neutrality difficult". (HOFFMAN, 1963, p.325). Além disso, a crítica a Hobbes também recai em sua visão sobre a natureza humana belicosa, visto que Rousseau compreende que o estado de guerra não é natural ao homem, pois "a guerra nasce da paz, ou pelo menos das precauções tomadas pelos homens para garantir uma paz duradoura" (ROUSSEAU, 2003a, p.57).

A corrupção do homem na sociedade se mostra latente no mais puro pessimismo de Rousseau ao enfatizar que a paz ampla e duradoura traria indiscutíveis vantagens para o comércio, mas ao mesmo tempo não seria apreciada, visto que os "benefícios só são percebidos pelo contraste, e quem queira aumentar o seu poder relativo se interessará apenas por ganhos que sejam exclusivos" (ROUSSEAU, 2003c, p.104). Além disso, os ministros dos príncipes têm interesse na guerra como um meio de se tornarem indispensáveis ao soberano de "criar-lhe dificuldades das quais não possa escapar sem a sua ajuda, de arruinar o Estado, na pior das hipóteses, como preço a pagar para manterse no cargo" (ROUSSEAU, 2003c, p.104).

Na concepção rousseauniana de Estado ideal, assim como existiriam limites para a estatura humana, um Estado também deveria limitar sua extensão a fim de que não venha "a ser nem muito grande para poder ser bem governado, nem muito pequeno para 
se manter por si mesmo" (ROUSSEAU, 2011). E como Sarti (2012, p.18) argumenta, ao mesmo tempo em que este Estado ideal seja constituído pela vontade geral, não significa dizer que bons Estados "levam necessariamente à paz duradoura".

\begin{abstract}
A desigualdade dos homens tem limites impostos pela natureza, mas a desigualdade das sociedades pode aumentar incessantemente, até que uma delas absorva todas as outras. Portanto, como a dimensão do organismo político é relativa, o Estado é obrigado a comparar-se para se conhecer; depende de todo o seu ambiente e precisa interessar-se por tudo o que acontece ali. Em vão quer permanecer dentro de suas fronteiras, sem nunca ganhar ou perder território; torna-se grande ou pequeno, forte ou fraco segundo a medida em que seus vizinhos se expandam ou diminuam, fiquem mais fortes ou mais fracos. Por fim, sua consolidação, tornando as suas relações mais constantes, atribui maior certeza a todas as ações que pratica e faz com que os seus conflitos se tornem mais perigosos (ROUSSEAU, 2003a; p.51).
\end{abstract}

Rousseau é crítico à guerra e aponta justamente que as disputas entre Estados causam tantas perdas do ponto de vista de recursos humanos e econômicos que não compensam em termos de conquista ou de ganhos de poder. Todavia, como a vontade geral é incapaz de administrar as vontades de cada Estado no sistema internacional, as guerras são inevitáveis. Isso não significa dizer que existe uma anarquia na arena internacional como argumenta Hobbes, mas que há uma incapacidade dos Estados de instituírem a paz duradoura (SARTI, 2012; HOFFMAN, 1963; ROUSSEAU, 2003a; 2003b; 2003c; 2003d).

Por fim, cabe menção breve a tese sobre a Polônia (1772) onde o autor argumenta sobre como a Polônia deveria constituir seu Estado. Rousseau apresenta novamente a potencialidade conflituosa do sistema internacional argumentando sobre a posição geográfica polonesa como um problema, tendo em vista que é o país cercado por potências belicosas. A partir destas ameaças no sistema uma das importantes sugestões de Rousseau é que a Polônia deveria constituir, por exemplo, seu exército somente com homens que são soldados por dever e não por profissão. Afinal, armar-se é um perigo mediante aos olhares de seus vizinhos que desconfiados, podem tentar impedir e esmagar rapidamente os poloneses (ROUSSEAU, 2003d).

A guerra não é uma necessidade humana ou uma força motriz, a guerra é uma instituição social, por isso as guerras seriam competições entre os Estados, ou seja, órgãos artificiais, mas não entre os indivíduos que podem somente lutar e cometer assassinatos 
(HOFFMAN, 2010, p.45). Nesse sentido, vale ressaltar que o pessimismo de Rousseau em nenhum momento afasta a tese central da natureza humana em sua mais pura forma como "boa", não sendo semelhante à tese hobbesiana que entende que a natureza humana não é modificada na sociedade civil, mas sim enclausurada devido às leis 9 .

\section{IMMANUEL KANT: O IMPERATIVO CATEGÓRICO PARA A PAZ DURADOURA}

Immanuel Kant (1724-1804) viveu no século XVIII e assim como Rousseau, foi fortemente influenciado pelo Iluminismo. As obras de Rousseau e Kant conversam na medida em que ambos tecem teorias a partir de análises da obra de Abbé Saint Pierre. A obra de Kant analisada neste artigo é $A$ Paz Perpétua (1795) e por meio da discussão a respeito das noções de paz, guerra e do homem, objetivamos demonstrar a visão da paz kantiana.

O projeto da Paz Perpétua de Kant tem como uma das principais características a busca pela correção da falta de relação jurídica entre os Estados no cenário internacional. A ausência os leva a estarem em um Estado de Natureza e, portanto, em um Estado de Guerra. Nas palavras de Kant:

O estado de paz entre os homens que vivem juntos não é um estado de natureza (status naturalis), o qual é antes um estado de guerra, isto é, um estado em que, embora não exista sempre uma explosão das hostilidades, há sempre todavia uma ameaça constante. Deve, pois, instaurar-se o estado de paz; a omissão de hostilidades não é ainda a garantia de paz e, se um vizinho não proporcionar segurança a outro (o que só pode acontecer num estado legal), cada um pode considerar como inimigo a quem lhe exigiu tal segurança (KANT, 2006, p.10).

O pensamento teórico de Kant compreende para além de conceitos sobre uma paz passageira ou um intervalo de tempo em que a paz é possível, argumenta-se sobre o estabelecimento de uma paz duradoura. Objetivando alcançar determinada paz, Kant enumera artigos necessários para que esta paz seja possível de se concretizar e de se perpetuar no cenário internacional. Em seu argumento a existência de tal paz só se tornaria possível diante de algumas leis e da própria estrutura de cada Estado neste sistema. Para detalhar a sua visão, o autor cria uma espécie de receita, onde existiriam artigos preliminares que estabelecem leis proibitivas, isto é, condições negativas para a paz perpétua e, por conseguinte, três constitutivos, favoráveis para o alcance da paz.

\footnotetext{
${ }^{9}$ Para ver mais sobre a concepção de Rousseau a respeito do cenário internacional ver Hoffman (1963).
} 
Os primeiros seis artigos são as necessidades prévias para o estabelecimento da paz, por isso são considerados preliminares.

1) Não deve considerar-se válido nenhum tratado de paz que tenha sido celebrado com a reserva secreta sobre alguma causa de guerra no futuro (KANT, 2006, p.57).

0 primeiro artigo preliminar é pensando devido ao próprio Tratado de Basiléia de abril de 1795 entre França e Prússia, esse tratado que um retrato de uma paz finita, uma reserva para uma guerra futura (LIMA, 2010). Ou seja, um tratado de paz não tem como alcance último a paz perpétua, mas sim o fim de uma guerra específica, em um momento particular e em circunstâncias peculiares, um impeditivo e uma falácia para aqueles que esperam a paz perpétua.

2) Nenhum Estado independente (grande ou pequeno) poderá ser adquirido por outro mediante herança, permuta, compra ou doação (KANT, 2006, p.58).

No segundo artigo o autor elenca sobre a resguarda para guerras futuras, onde nenhum Estado pode ser considerado como patrimônio privado, mas deve ser considerado público visto que foi instituído de maneira coletiva e fundamentado em uma Constituição.

3) Os exércitos permanentes devem desaparecer totalmente com o tempo (KANT, 2006, p. 59).

Nota-se que o terceiro artigo preliminar talvez seja um dos mais criticados para a concretização do pensamento kantiano, tendo em vista que a eliminação de um exército pode ser encarada como inviável diante de um cenário atual, por exemplo, em que não só são mantidos exércitos, mas como anualmente são aumentados os gastos com defesa e segurança no cenário internacional. No argumento de Kant os exércitos constituem um princípio paradoxal, pois ao mesmo tempo em que servem para proteger o Estado e para lutar a guerra com o intuito de alcançar a paz, sua existência cria um caráter incessante de disputa e de poder que até mesmo Rousseau menciona na obra sobre a Polônia, como elencamos anteriormente. 
4) Não deve emitir-se dívida pública em relação aos assuntos de política exterior (KANT, 2006, p.59)

O quarto artigo é um exemplo das preocupações a respeito do endividamento de Estados durante as guerras e como tais dívidas são empecilhos para o estabelecimento da paz. As dívidas desgastam alguns Estados e enriquecem outros, ao mesmo tempo em que financiam a continuidade da guerra.

5) Nenhum Estado deve interferir, através da força, na constituição e no governo de outro (KANT, 2006, p.60).

O princípio da não-intervenção de Estados no âmbito doméstico tem como justificativa o fato de que alianças entre elites ou até mesmo entre determinados grupos nas sociedades podem causar guerras e desavenças e, além disso, podem causar danos à gerência dos próprios atores dentro dos Estados.

6) Nenhum Estado em guerra com outro deve permitir-se hostilidades tais que façam impossível a confiança mútua na paz futura, como o emprego, em outro Estado, de assassinos, envenenadores, a quebra de acordos, a indução à traição, etc. (KANT, 2006, p.61)

0 último artigo elenca a importância da condução da guerra de determinadas formas para que não haja no futuro uma maior desconfiança entre os Estados fruto de uma guerra passada.

Os artigos que enumeramos são as necessidades prévias para o estabelecimento da paz, por isso são preliminares. Também existem os artigos definitivos para a Paz Perpétua e através do cumprimento deles seria possível pensar em um projeto de paz duradouro. Os artigos são três e seriam eles:

1) A constituição civil de todo Estado deve ser republicana;

2) 0 Direito de Gentes deve fundamentar-se em uma federação de Estados livres;

3) 0 Direito Cosmopolita deve limitar-se às condições da hospitalidade universal. (KANT, 2006, pp. 62-65). 
0 primeiro artigo se refere à constituição da paz sobre Estado alicerçada na constituição republicana que seria regida por três princípios: i) a liberdade, ii) a dependência de todos a uma legislação comum e iii) a igualdade de todos enquanto cidadãos (LIMA, 2010, p.127). O segundo artigo justifica que a partir da federação de Estados livres seria viável criar a federação da paz que procuraria por fim a todas as guerras. E no último artigo, o papel fundamental que o direito cosmopolita exerce na filosofia kantiana pode ser notado e a partir artigo o estrangeiro não ser tratado com hostilidade em virtude de sua saída de um território para o outro.

De acordo com Hoffman (1963, p.31) assim como Rousseau, Kant identifica no homem a paz e a moralidade considerando que o homem que obedece ao imperativo da moralidade, deseja a paz. Entretanto, enquanto a batalha entre os desejos egoístas dos homens e sua moral imperativa no momento em que ele passa a se inserir na sociedade é descrita em Rousseau; Kant "sees this battle as a permanent feature of man: the moral imperative is already at work in the state of nature; it is that very imperative which creates a duty to get ou of the state of nature". Enquanto a sociedade corrompe o homem de Rousseau, para Kant a sociedade é uma condição para o progresso moral.

Ainda assim, Kant acredita que todo "o povo encontraria ante si outro povo que o ameaça, e o contra o qual deve converter-se internamente em um Estado, para estar preparado como potência contra aquele" (KANT, 2006, p.89). Para tanto, a existência de uma paz permanente, seria necessária a existência de um número suficientemente grande de governos republicanos, e que iriam abdicar do recurso à guerra como instrumento de interação no contexto internacional.

Orend (1999, p.332), em seu argumento sobre como se constitui o Estado kantiano, compreende que na visão do autor devemos sair de um Estado de anarquia nas relações internacionais para um tipo de sociedade civil cosmopolita. A sociedade só pode ser constituída mediante à visão objetiva dos princípios jurídicos que norteiam todo o pensamento kantiano, para tanto, os Estados têm direitos vis-à-vis uns aos outros porque “1) their citizens, as individuals, have human rights; and 2) in order to secure the objects of these human rights from possible deprivation by outsiders, a collective agency, like the state, needs to be authorized, or entitled, to certain objects and actions in its own right, vis-a-vis these non members and the collective agencies which act on their behalf'. 
De acordo com Kant existiria uma tendência na história humana de tornar realidade uma sociedade em que o direito traria condições para tornar a paz pacífica. Portanto, segundo o autor os Estados estão em constante Estado de Guerra nas suas relações uns com os outros, o Estado natural é um Estado de Guerra e a forma de constituir o Estado civil decorre do imperativo categórico que é a máxima que estabelece a diretriz, é um dever moral universalmente válido que é definido como "age de tal modo que possas querer que a tua máxima se torne uma lei universal (seja qual for o fim que ele queira)" (KANT, 2006, p.41).

A paz duradoura de Kant só é possível mediante a adoção de uma constituição republicana, mas é necessário que todos os Estados cumpram com os três artigos constitutivos, visto que "se um destes Estados numa relação de influência física com os outros estivesse em estado da natureza, isso implicaria o estado de guerra, de que é justamente nosso propósito libertar-se" (KANT, 2006, p. 10-11).

\section{CONSIDERAÇÕES FINAIS}

No debate acima tentamos demonstrar a visão teórica dos autores ressaltando os aspectos relacionados à paz e à guerra. Existem inúmeros autores das ciências humanas que se preocupam com tal temática e este artigo teve o interesse de ampliar o debate ressaltando algumas semelhanças entre os autores e os alicerces de suas teorias. A Paz e a Guerra tanto em Rousseau, como Hobbes e Kant são alguns dos cenários que servem para justificar tanto a natureza humana como a própria concepção de Estado para os autores: de que forma ele poderia surgir e o que ele consegue ou não corrigir no homem, na sociedade ou na relação entre Estados, estes são pontos apresentados nas obras dos autores.

De forma resumida, os três autores enxergam a paz como um desejo máximo dos homens, a busca pela segurança, os anseios pela sobrevivência e por uma vida tranquila são norteadores da vida humana. Todavia, diferenciam-se justamente no argumento sobre se a paz é possível de ser instaurada no cenário internacional ou não.

Como demonstramos, a guerra em Hobbes tem um caráter incessante no Estado de Natureza e só é sanada no momento em que é realizado o contrato por meio do qual os homens instituem o Estado. Todavia, apesar da guerra ser sanada do ponto de vista 
doméstico, no cenário internacional continua a imperar a guerra "de todos contra todos" devido a inexistência de impedimentos e de uma figura soberana capaz de regular a relação entre os Estados, para tanto, o cenário internacional é marcado pela anarquia.

Rousseau, diferente de Kant e Hobbes, enxerga no Estado de Natureza como o momento em que o homem vive de forma pacífica, onde todos são iguais e vivem livres. No momento em que o homem passa a viver em sociedade, ele se torna refém de grilhões de um contrato que foi estabelecido sem que ele tivesse real noção de suas cláusulas, o homem era ingênuo. A guerra existe na sociedade e o homem deveria buscar pela mesma harmonia que uma vez existiu no Estado de Natureza. Todavia, assim como Hobbes, no cenário internacional rousseauniano não prevalece a paz e não existem meios para o estabelecimento de uma paz duradoura, como demonstramos em suas críticas a Abbé Saint Pierre. 0 pessimismo de Rousseau argumenta sobre a mesma inviabilidade da paz do cenário internacional, um ambiente que gera guerra e conflito,

Por fim, Kant apresenta como o ideal dos homens o estabelecimento da paz e argumenta sobre condições necessárias para o estabelecimento de tal paz. A paz deve ser duradoura e não um momento momentâneo que é gerado por tratados e armistícios. No Estado de Natureza é também um momento de conflitos, onde não existiriam leis, e devido a racionalidade presente no homem, o Estado de direito deveria ser instalado para preservar a paz, a liberdade e a igualdade dos homens. Diferente de Rousseau, a vida em sociedade é uma etapa para o progresso humano e não a sua corrupção. No cenário internacional a guerra existe, mas diferente dos outros dois autores aqui apresentados, a paz duradoura é possível.

A paz e a guerra são temas que ainda precisam ser pesquisados e as alternativas e meios para o estabelecimento da paz ainda precisam ser pensados, visto que como é mencionado por Niall Ferguson (2015: p.32) "os cem anos depois de 1900 foram, sem dúvida, o século mais sangrento da história moderna, muito mais violentos, tanto em termos relativos quanto em termos absolutos, que qualquer era anterior".

Os escritos desses autores são algumas das bases para as teorias da Ciência Política e das Relações Internacionais. 0 debate sobre a necessidade do estabelecimento da ordem no sistema internacional, o debate acerca da paz e da guerra não deixou de ser atual e é algo que tem um fluxo contínuo devido às guerras ou o risco do acontecimento 
da mesma que acontecem todos os dias seja no Oriente Médio, no Leste Asiático, na África, por fim, no mundo todo.

\section{REFERÊNCIAS BIBLIOGRÁFICAS}

AQUINO, São Tomás. Suma Teológica. Biblioteca de Autores Cristianos. Madrid. 2001. Disponível em: http://biblioteca.campusdominicano.org/1.pdf Acesso em: 18 de abril de 2016.

AUGUSTINE, de Hipona St. The City of God. Modern Library. New York. 2000.

BULL, Hedley. Hobbes and the International Anarchy. Social Research, Vol. 48, No. 4, Politics: The Work of Hans Morgenthau, 1981, pp. 717-738.

CLAUSEWITZ, Carl Von. Da Guerra. CEPE. Escola de Guerra Naval. Epub. S/D Disponível em: https://www.egn.mar.mil.br/arquivos/cepe/DAGUERRA.pdf Acesso em: 14 de junho de 2015.

FERGUSON, Niall. A Guerra do Mundo. Editora Planeta. São Paulo. 2015.

GALTUNG, Johan. Violence, Peace, and Peace Research.Journal of Peace Research, Vol. 6, No. 3, 1969, pp. 167-191.

HOBBES, Thomas. Leviatã ou matéria, forma e poder de um Estado Eclesiástico e civil. São Paulo. Martin Claret, 2009.

. De Cive. The English Version. Clarendon Press, Oxford. 1983.

HOFFMAN, Stanley. Rousseau on War and Peace. The American Political Science Review, Vol. 57, No. 2. 1963, pp. 317-333.

. Rousseau sobre a Guerra e a paz. Videre, Dourados, Mato Grosso do Sul, ano

2, n. 3, p. 27-64, jan./jun. 2010.

KANT, Immanuel. Para a paz perpétua. Instituto Galego de Estudos de Segurança Internacional e da Paz. Ensaios sobre paz e conflitos. Vol. 5. Galiza. 2006.

KEENE, Edward. Beyond the Anarchical Society. Grotius, Colonialism and Order in World Politics. Cambridge University Press, Oxford. 2004.

LEOPOLDI, José. Rousseau - estado de natureza, o "bom selvagem" e as sociedades indígenas. ALCEU, Volume 2, №4, jan./jun. 2002, pp. 158-172.

LIMA, Francisco Jozivan. As condições de possibilidade de efetivação da paz perpétua segundo Kant. Revista de opinião filosófica. n. 02, v.01 Artigo, 2010, pp. 118-133

MORGENTHAU, Hans J. A política entre as nações: a luta pela guerra e pela paz. Brasília. Imprensa Oficial do Estado de São Paulo. 2003. 
ONUF, Nicholas. Constructivism: A User's Manual In: VENDULAKA, K; ONUF, N; KOWERT, P. International Relations in a Constructed World. Routledge, London and New York. 2015, pp.25-57.

OREND, Brian. Kant's Just War Theory. Journal of the History of Philosophy, The Johns Hopkins University Press, Volume 37, Number 2, April 1999, pp. 323-353

ROUSSEAU, Jean-Jacques. Do Contrato Social. Penguim. Companhia das Letras, Epub. 2011, São Paulo.

o Estado de Guerra Nascido do Estado Social. In: Jean-Jacques. Rousseau e as Relações Internacionais. Coleção Clássicos IPRI. Editora UNB. São Paulo, 2003a, pp.49-54.

. Considerações Sobre o Governo da Polônia e a sua projetada Reforma In: JeanJacques. Rousseau e as Relações Internacionais. Coleção Clássicos IPRI. Editora UNB. São Paulo, 2003d, pp.221-310.

. Extrato e Julgamento do Projeto de Paz Perpétua de Abbé de Saint-Pierre. In: JeanJacques. Rousseau e as Relações Internacionais. Coleção Clássicos IPRI. Editora UNB. São Paulo, 2003c, pp.69-100.

. Fragmentos Sobre a Guerra. In: Jean-Jacques. Rousseau e as Relações Internacionais. Coleção Clássicos IPRI. Editora UNB. São Paulo, 2003b, pp.61-68.

SAINT-PIERRE, Abbé de. Projeto para Tornar Perpétua a Paz na Europa. IPRI/FUNAG. Editora UnB. 2003.

SARTI, Ingrid. Rousseau, do realismo crítico à utopia. In: Lima, M. C; Villa, R. D.; Medeiros, M. A.; Reis, R.R.(org.). Teóricos das Relações Internacionais. São Paulo/Brasília: Hucitec/Capes: 36-6, 2012.

SUN, Tzu . (2000) A ARTE DA GUERRA. Porto Alegre. Editora L\&PM.

WEFFORT, Francisco. Os Clássicos da política. Editora Ática. Volume 1. Dérie Fundamentos Epub. 2011.

WILLIAM, Michael. Hobbes and International Relations: A Reconsideration. MIT Press, International Organization, Vol. 50, No. 2, 1996, pp. 213-236. 